\title{
The secreted protein S100A7 (psoriasin) is induced by telomere dysfunction in human keratinocytes independently of a DNA damage response and cell cycle regulators
}

\author{
Alice de Castro', Fay Minty ${ }^{1}$, Eva Hattinger ${ }^{2}$, Ronald Wolf ${ }^{2}$ and Eric Kenneth Parkinson ${ }^{1,3^{*}}$
}

\begin{abstract}
Background: Replicative senescence is preceded by loss of repeat sequences of DNA from the telomeres that eventually leads to telomere dysfunction, the accumulation of irreparable DNA double strand breaks and a DNA damage response (DDR). However, we have previously reported that whilst telomere dysfunction in human keratinocytes is associated with a permanent cell cycle arrest, the DDR was very weak and transcriptional profiling also revealed several molecules normally associated with keratinocytes terminal differentiation, including S100A7 (psoriasin).
\end{abstract}

Results: We show here that S100A7 and the closely related S100A15 (koebnerisin) are not induced by repairable or irreparable DSBs, ruling out the hypotheses that these genes are induced either by the low DDR observed or by non-specific cell cycle arrest. We next tested whether S100A7 was induced by the cell cycle effectors ARF (p14 ARF), CDKN2A (p16 ${ }^{\text {NK4A }}$ ) and TP53 (p53) and found that, although all induced a similar level of acute and permanent cell cycle arrest to telomere dysfunction, none induced S100A7 (except p53 over-expression at high levels), showing that cell cycle arrest is not sufficient for its induction. The closely related transcript S100A15 was also upregulated by telomere dysfunction, to a similar extent by $\mathrm{p} 16^{\mathrm{INK} 4 \mathrm{~A}}$ and $\mathrm{p} 53$ and to a lesser extent by p14 ${ }^{\mathrm{ARF}}$.

Conclusions: Our results show that mere cell cycle arrest, the upregulation of senescence-associated cell cycle effectors and DNA damage are not sufficient for the induction of the S100 transcripts; they further suggest that whilst the induction of S100A15 expression is linked to both telomere-dependent and -independent senescence, S100A7 expression is specifically associated with telomere-dependent senescence in normal keratinocytes. As both S100A7 and S100A15 are secreted proteins, they may find utility in the early detection of human keratinocyte telomere dysfunction and senescence.

Keywords: Telomere, Senescence, Keratinocyte, Differentiation, SASP, S100

\section{Background}

Senescence is defined as a permanent cell cycle arrest that occurs following extensive cell divisions (replicative senescence, RS) or more acutely following a variety of cellular stresses (stress- or proliferation-induced senescence). In addition to engaging a permanent cell cycle

\footnotetext{
* Correspondence: e.k.parkinson@qmul.ac.uk

${ }^{1}$ Centre for Clinical \& Diagnostic Oral Sciences, Institute of Dentistry, Barts and the London School of Medicine and Dentistry, Queen Mary University of London, Turner Street, London E1 2AD, UK

${ }^{3}$ Blizard Building, 4, Newark Street, London E1 2AT, UK

Full list of author information is available at the end of the article
}

arrest, senescent cells secrete a variety of proteins known as the senescence-associated secretory phenotype (SASP) or senescence-messaging-secretome [1,2]. These types of proteins are of extra interest because they may find a use in the non-invasive detection of senescent cells in ageing and other pathologies [3].

RS occurs following extensive rounds of cell division and is accompanied by the erosion of the chromosomal telomeres [4]. Telomeres are repeat sequences of DNA, TTAGGG and their associated proteins, which are known as the shelterin complex $[5,6]$ and protect the 
DNA ends from being perceived by the cell as a DNA double strand break (DSB). Telomeres will shorten when cells divide in the absence of telomerase due to either the end replication problem $[4,7,8]$, exonuclease digestion [9] or, in some circumstances, oxidative damage $[10,11]$. This culminates in the telomere being perceived as a DSB [12] and most senescent cells mount a significant DDR [13]. In addition, the G-rich telomere sequences are susceptible to oxidative damage and very inefficient at non-homologous end-joining repair leading to a preferential accumulation of irreparable DSBs (IrrDSBs) at the telomere $[14,15]$. Telomerase is deregulated in most human cancers including oral squamous cell carcinoma (OSCC [16]) and can immortalise normal and neoplastic keratinocytes that lack the expression of the INK4A locus or a combination of $\mathrm{p} 53$ and $\mathrm{p} 16^{\mathrm{INK} 4 \mathrm{~A}}$ proteins by lengthening the telomeres and restoring their function [17]. Telomerase has also been reported to remove the IrrDSBs at telomeres, but it is not clear whether this property is related to its canonical telomere-lengthening function [18].

Although keratinocyte stem cells are not thought to decrease in number during in vivo ageing [19], there is considerable evidence that they undergo an age-related loss of function (reviewed in [20]); as with increased chronological age, their progeny display increased levels of stochastic senescence in vitro [21] telomeric attrition [22-24] and an accumulation of $\mathrm{p} 16^{\mathrm{INK} 4 \mathrm{~A}}[25,26]$, the last of which is reported to be inversely associated with longevity [26].

Telomere dysfunction and its associated DDR can be induced along with senescence by over-expressing a dominant-negative mutant of the shelterin protein telomere-repeat binding factor 2 (TRF2), TRF2 delta B delta $M\left(T R F 2^{\triangle B \Delta M}\right.$ or TRF2DN) [12]. However, although this manipulation induces permanent cell cycle arrest [27] and leads to underphosphorylated pRb (Minty and Parkinson, unpublished data), it does not generate a strong DDR in normal human keratinocytes, as exemplified by a lack of strong induction of p53 phosphorylation at serine 15 , or $53 \mathrm{BP} 1$ foci and no detectable increase in p21 WAF [28] or SMC1-phosphoS966 or Nbs1-phosphoS343 (Minty and Parkinson, unpublished data). In contrast, all of these DDR markers were induced by $8-16$ gray of ionising radiation in a dosedependent manner and p53 stabilisation by as low a dose as 1 gray ([28] and Minty and Parkinson, unpublished data). Similar results are seen when a neoplastic keratinocyte line, D17, lacking expression of p16 ${ }^{\text {INK4A }}$ undergoes RS and telomere shortening [28]. Instead, in both situations, we observed an induction of several genes normally associated with keratinocyte terminal differentiation, including HOPX and S100A7 and other genes not obviously related to differentiation (ICEBERG and the histone HIST2H2BE); in D17, we also observed a reduction in expression of all of these genes upon expression of telomerase in parallel with telomere lengthening, senescence bypass and an elimination of the very small increase in $\mathrm{p} 53$ phosphorylation at serine 15 [28]. As these genes showed potential as markers of telomere dysfunction, we investigated them further.

Our earlier work stimulated the hypothesis that signals other than DNA double strand breaks and the DDR could be generated from dysfunctional telomeres to increase the expression of proteins that might have diagnostic use. S100A7 was of particular interest as its encoded protein is secreted by keratinocytes and is found in detectable amounts in human serum where it has found utility as a non-invasive marker of a subtype of lung cancer [29].

Alternatively, the small DDR observed in keratinocytes following telomere uncapping or shortening might be enough to induce the terminal differentiation genes. Indeed, DNA damage has been shown to contribute to tissue ageing by the induction of terminal differentiation [30]. To test this hypothesis, we examined the effects of both low- and high-dose ionising radiation [28,31] on the expression of the genes induced by telomere dysfunction and showed that S100A7 was not increased in expression relative to the non-irradiated controls.

Additionally, the increased expression of keratinocyte differentiation genes could be a consequence of any form of senescence or growth arrest. To test this hypothesis and to investigate the role of the cell cycle proteins involved in senescence, we ectopically expressed ARF (p14 ${ }^{\mathrm{ARF}}$ ), CDKN2A (p16 ${ }^{\mathrm{INK} 4 \mathrm{a}}$ ) and TP53 (p53) in human keratinocytes and showed that, despite similar levels of growth arrest, these manipulations did not induce the expression of S100A7 (except for high levels of p53), although all three induced the expression of the S100A15 (koebnerisin) gene, which is highly homologous to S100A7 (psoriasin) and difficult to discriminate when co-regulated. Their differential regulation by cell cycle inhibitors suggests that both S100 proteins have different functions that need to be further studied.

As the S100A7 protein was potentially a specific marker of telomere dysfunction, we investigated this further and showed it to be increased in normal keratinocytes following the induction of telomere dysfunction by the dominantnegative TRF2 construct TRF2 ${ }^{\triangle B \Delta M}$.

\section{Results and discussion}

Markers of keratinocyte telomere dysfunction are not induced by DNA double strand breaks

In order to test whether the small DDR observed following keratinocyte telomere uncapping or shortening [28] was responsible for the induction of HIST2H2BE, ICE$B E R G, H O P X$ and $S 100 A 7$, we exposed normal human keratinocytes to 2,10 or 20 gray of ionising radiation 
(IR). All of these doses have been shown by ourselves ([28] and Minty and Parkinson, unpublished data) and others [31] to generate a strong DDR.

The low dose of 2 gray was previously calculated to mimic the number of DNA double strand breaks generated by the transient uncapping all 92 telomeres by over-expressing $T R F 2^{\Delta B \Delta M}$. The 10 - and 20-gray doses induce senescence in all the keratinocytes in the population by introducing IrrDSBs. An ionising radiation dose of 2 gray induced $\mathrm{p} 21^{\mathrm{WAF}}$ transcript and protein, supporting previous data [28] that a significant DDR was generated (Figure 1a). However, the 2-gray dose did not reduce the levels of cyclin A2 and cyclin D1 transcript [32] (Figure 1b) as these transcripts take longer than 6 $\mathrm{h}$ to reduce and did not induce the early stages of terminal differentiation as assessed by involucrin transcript (Figure 1b). If anything, HIST2H2BE, ICEBERG and $H O P X$ levels decreased slightly, and although S100A7/S100A15 levels increased by $40 \%$, this was not statistically significant (Figure 1c). Thus, the transient levels of DNA damage induced by telomere uncapping do not explain the previously reported induction of HIST2H2BE, ICEBERG, HOPX and S1OOA7 transcripts [28], excluding this as a mechanism. However, as 2-gray irradiated cells were not growth arrested, let alone senescent, we tested the hypothesis that irreparable DNA double strand breaks, which are well known to cause senescence [31], could induce HIST2H2BE, ICEBERG, HOPX and $S 100 A 7$ transcripts. Figure $2 \mathrm{a}$ shows that 5 days following irradiation, $\mathrm{p} 21^{\mathrm{WAF}}$ transcript and both $\mathrm{p} 21^{\mathrm{WAF}}$ and $\mathrm{p} 53$ proteins were elevated in keratinocytes irradiated with both 10 and 20 gray and both doses of radiation reduced cyclin A2 transcript and induced cyclin D1 transcript (Figure 2b), both markers of senescence [32] and blocked keratinocyte multiplication (Figure 2c-cell yields). There was no evidence that IR-induced irreparable damage induced terminal differentiation as assessed by involucrin transcript levels (Figure 2b) or by increased colony size (data not shown), although $\mathrm{p} 21^{\mathrm{WAF}}$ expression was greater with increased colony size at day 5 (data not shown), consistent with the established association of $\mathrm{p} 21^{\mathrm{WAF}}$ with keratinocyte differentiation where its expression promotes the initial commitment of keratinocyte stem cell populations to differentiation [33] and contributes to differentiation-associated growth arrest [34]. Despite this, there was no observable induction of any of the genes of interest 5 days after IR, except HIST2H2BE (Figure 2d), which increased nearly twofold in both radiation doses and was significant at 20 gray. These experiments thus support the hypothesis that the irreparable DNA damage at the telomere induced by telomere uncapping could possibly be responsible for the induction of $H I S T 2 H 2 B E$; although at this stage, non-specific growth arrest could not be ruled out.
Nevertheless, these results reject the hypothesis that the low levels of DDR engendered by telomere uncapping were responsible for the induction of ICEBERG, HOPX and S100A7/S100A15 expression. The results also argue against the hypothesis that these induced transcripts are the result of non-specific growth arrest, an assertion supported by the next set of experiments.

\section{The induction of permanent growth arrest by the cell cycle effectors ARF/p $14^{\mathrm{ARF}}$, CDKN2A/p $16^{\text {INK4A }}$ and TP53/ p53 does not replicate the effect of $T R F 2^{\triangle B \Delta M}$ on the expression of HIST2H2BE, ICEBERG, HOPX and S100A7}

In order to further test the specificity of ICEBERG, HOPX and $S 100 A 7 / S 100 A 15$ as markers of telomere dysfunction and to test the role of the downstream senescence effector proteins in their expression, we over-expressed $\mathrm{p} 16^{\mathrm{INK} 4 \mathrm{~A}}, \mathrm{p} 14^{\mathrm{ARF}}$ and $\mathrm{p} 53$ in normal human epidermal keratinocytes and compared them with the ectopic expression of TRF2 ${ }^{\triangle B \Delta M}$. Figure 3a shows the effects of telomere uncapping by the ectopic expression of TRF2 $2^{\triangle B \triangle M}$ on the expression of HIST2H2BE, ICEBERG, HOPX and S10OA7 confirming our earlier report that $T R F 2^{\triangle B \Delta M}$ only induces expression of these genes at high levels of expression that cause a growth arrest illustrated by a $40 \%-50 \%$ reduction in CCNA2 expression (Figure 3b). However, none of the classical cell cycle effectors of senescence-associated cell cycle arrest were affected at day 5 by telomere uncapping in human keratinocytes (Figure 3c). To test the effect of $\mathrm{p} 14^{\mathrm{ARF}}, \mathrm{p} 16^{\mathrm{INK} 4 \mathrm{~A}}$ and $\mathrm{p} 53$, we ectopically expressed these transgenes in human keratinocytes and compared their effects on HIST2H2BE, ICEBERG, HOPX and S100A7/ $S 100 A 15$ transcripts with $T R F 2^{\triangle B \triangle M}$. All four transgenes caused similar changes in both CCNA2 and CCND1 expressions within 5 days (Figures $3 \mathrm{~b}, 4 \mathrm{~b}$ and Additional file 1: Figure S1b and Additional file 2: Figure $S 2 b$ ) and similar levels of long-term growth arrest as shown by a $75 \%$ reduction in colony-forming efficiency in all groups except p14 ${ }^{\mathrm{ARF}}$, which caused only a $50 \%$ reduction in colony-forming efficiency (Figure 5). The forced expression of $T R F 2^{\triangle B \Delta M}$ induced the expression of all four candidate markers as reported previously (Figure 4a) but did not induce the constitutive expression of any of the other transgenes tested within 5 days (Figure 4c). p16 ${ }^{\mathrm{INK} 4 \mathrm{~A}}$ did not induce the expression of ICEBERG, HOPX or S100A7/S100A15 (Figures 4a and 6) showing that the induction of a permanent growth arrest in the absence of signals upstream of $\mathrm{p} 16^{\mathrm{INK} 4 \mathrm{~A}}$ was not enough to cause the increased expression of the candidate markers of telomere dysfunction-induced keratinocyte growth arrest. However, p53 did induce increased ICEBERG expression, although somewhat inconsistently (Figure 6a, Additional file 1: Figure $\mathrm{S} 1 \mathrm{a}$ and Additional file 2: Figure S2a) and $\mathrm{p} 53$ and $\mathrm{p} 14^{\mathrm{ARF}}$ induced HOPX expression and to a lesser extent HIST2H2BE (Figure 6a, 

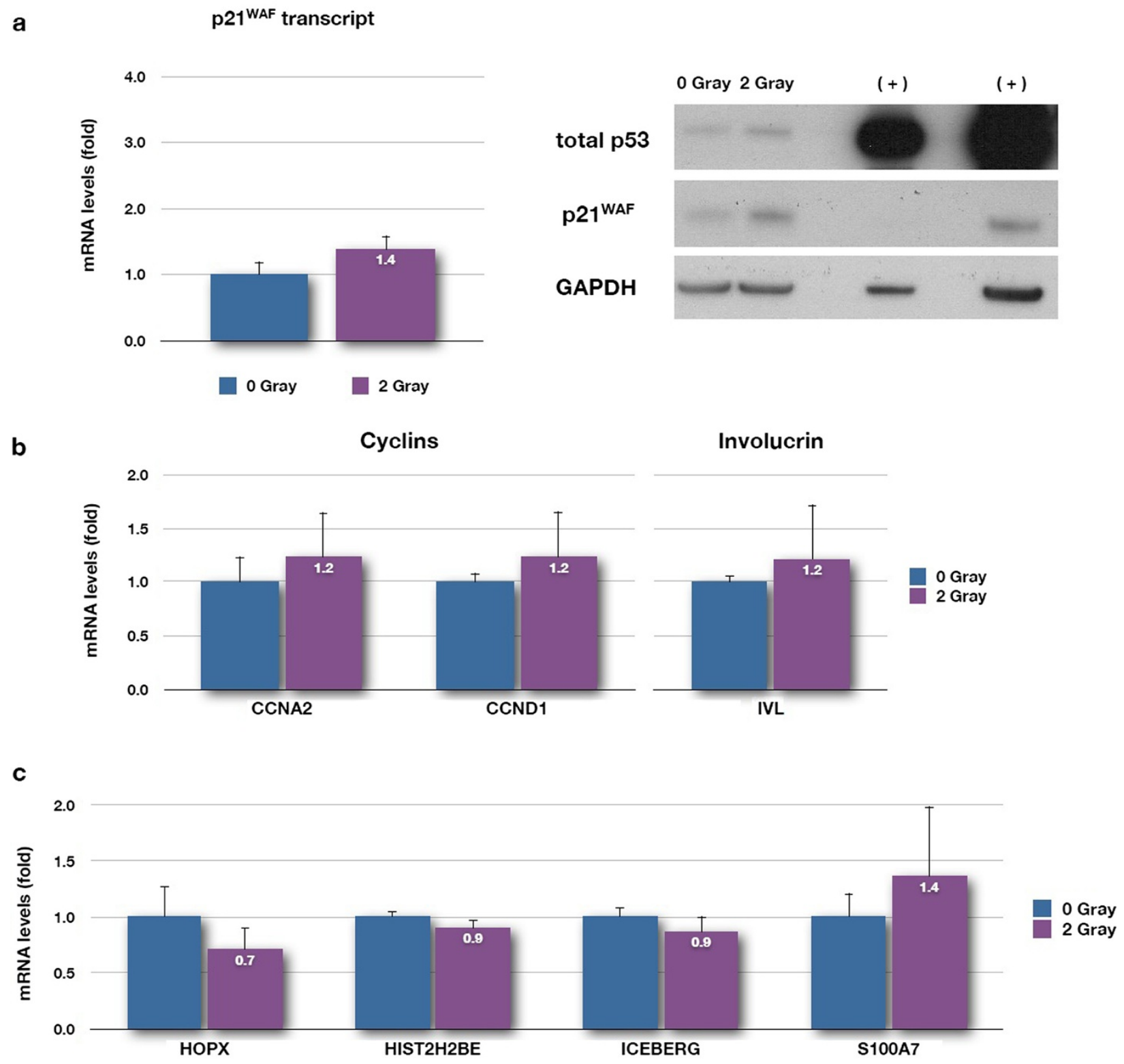

Figure 1 Repairable levels of DNA damage do not replicate the effects of telomere uncapping in keratinocytes. NHEKs were irradiated with 2 gray of IR and allowed $6 \mathrm{~h}$ to recover. Whole cell lysates were then prepared and analysed by reverse transcription quantitative PCR (RT-qPCR) and Western blotting for the indicated transcripts and proteins, respectively. (a) p2 $1^{\text {WAF }}$ transcript (graph), GAPDH, total p53 and p21 WAF proteins (blot). (b) Cyclin A2 (CCNA2), cyclin D1 (CCND1) and involucrin (IVL) transcripts. (c) HOPX, HIST2H2BE, ICEBERG and S100A7 (S100A7/S100A15) transcripts. Data are reported as a fold change in mRNA expression levels relative to the non-irradiated control (0 gray). Data are mean $\pm \mathrm{sd}$ from three independent measurements $(n=3)$ in $(b)$ and $(c)$; in $(a)$, only two out of the three independent measurements are represented. Legend: GAPDH, loading control; (+) symbol, positive control for total p53 and p21 WAF proteins (SVHFK cell line); last lane loaded with double the amount of total protein.

Additional file 2: Figure S2a), although there is no evidence that telomere uncapping induces high levels of p53 transcript (Figure 3c) or protein [28]. None of the transgenes induced the transcription of any of the other endogenous effectors of senescence, nor endogenous TRF2 (Figures 3c, 4c and Additional file 1: Figure S1c and Additional file 2: Figure S2c). No transgene, except $T R F 2^{\triangle B \Delta M}$ (and high levels of p53), induced S100A7 (Figure 6 transcript and protein), and for this reason, we pursued S100A7/S100A15 as potential biomarkers of telomere dysfunction in the absence of DNA double strand breaks and studied these further. 
4.0

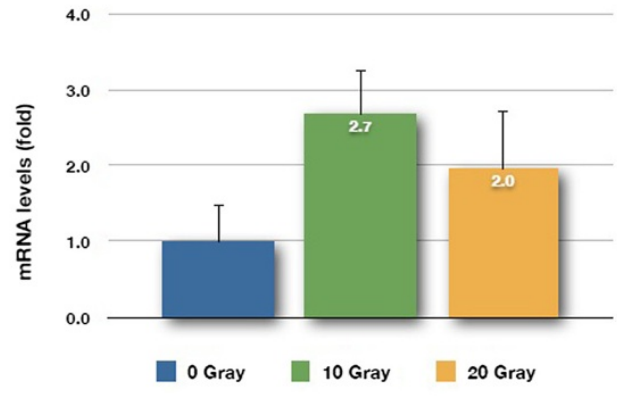

p21 WAF transcript

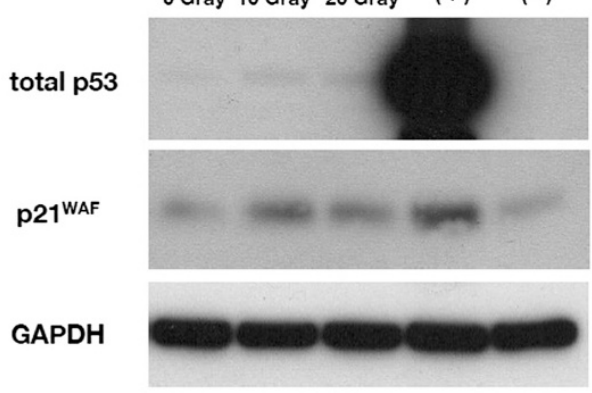

b

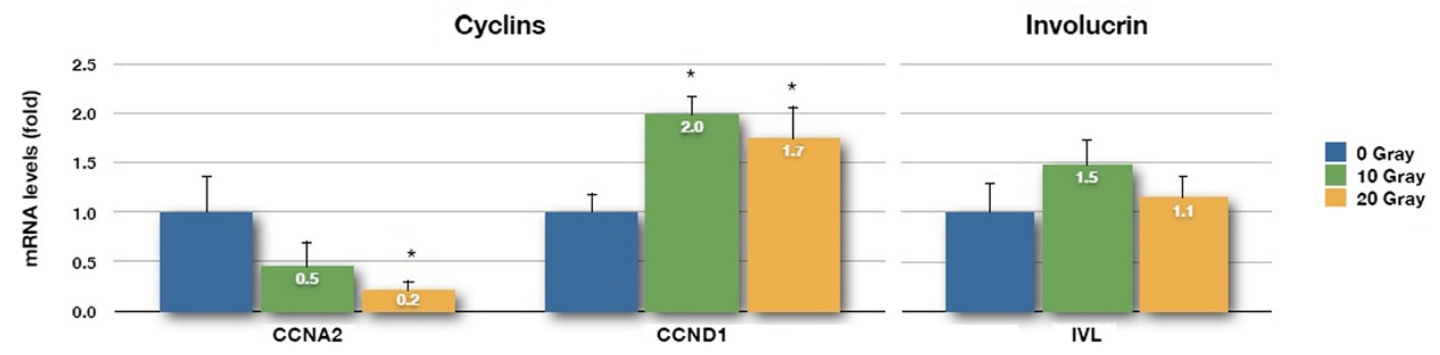

C
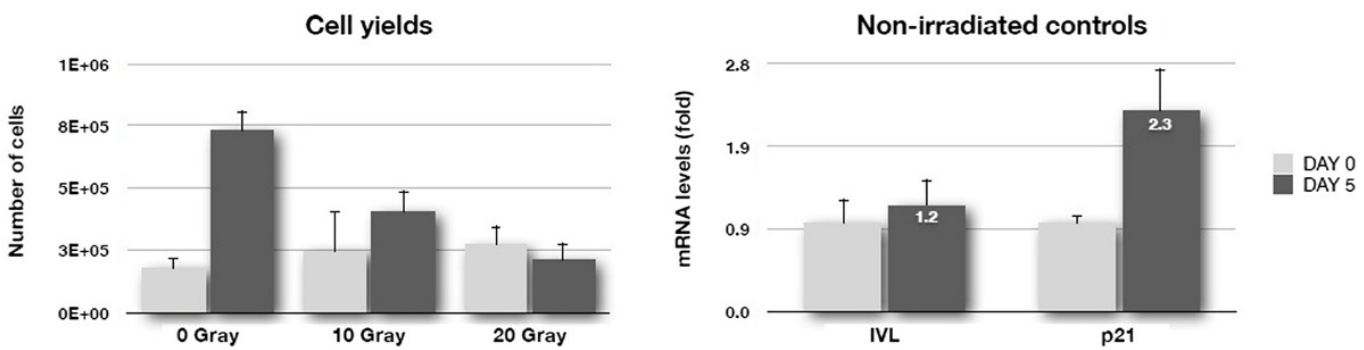

d

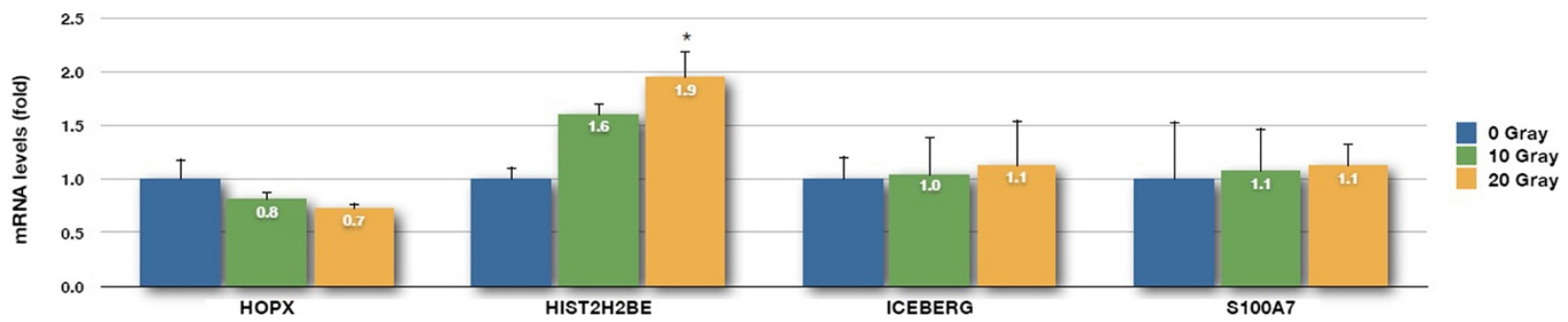

Figure 2 Irreparable levels of DNA damage induce HIST2H2BE transcription but not HOPX, ICEBERG or S100A7 (S100A7/S100A15). NHEKS were irradiated with 10 or 20 gray of IR and allowed 5 days to recover. Whole cell lysates were then prepared and analysed by RT-qPCR and Western blotting for the indicated transcripts and proteins, respectively. (a) p2 $1^{\text {WAF }}$ transcript (graph), GAPDH, total p53 and p21 WAF proteins (blot). (b) Cyclin A2 (CCNA2), cyclin D1 (CCND1) and involucrin (IVL) transcripts. (c) Total number of cells in all treated groups and p21 ${ }^{\text {WAF }}$ and IVL transcripts in non-irradiated controls, before (day 0) and after (day 5) the recovery period. (d) HOPX, HIST2H2BE, ICEBERG and S100A7 (S100A7/S100A15) transcripts. Data are reported as a fold change in mRNA expression levels relative to the non-irradiated control (0 gray) in (a), (b) and (d); in (c), data are reported as a relative fold change in mRNA expression levels between day 0 (immediately after irradiation) and day 5 (after the recovery period). Data are mean \pm sd from three independent measurements $(n=3)$ in (b), (c) and (d); in (a), only two out of the three independent measurements are represented. Asterisks $(p<0.05)$ indicate significant change in transcript levels relative to non-irradiated cells and were calculated by one-way ANOVA followed by Tukey's post hoc test. Legend: GAPDH, loading control; (+) symbol, positive control (SVHFK cell line); and (-) symbol, negative control (BICR-6 cell line) for total p53 and p21 WAF proteins. 


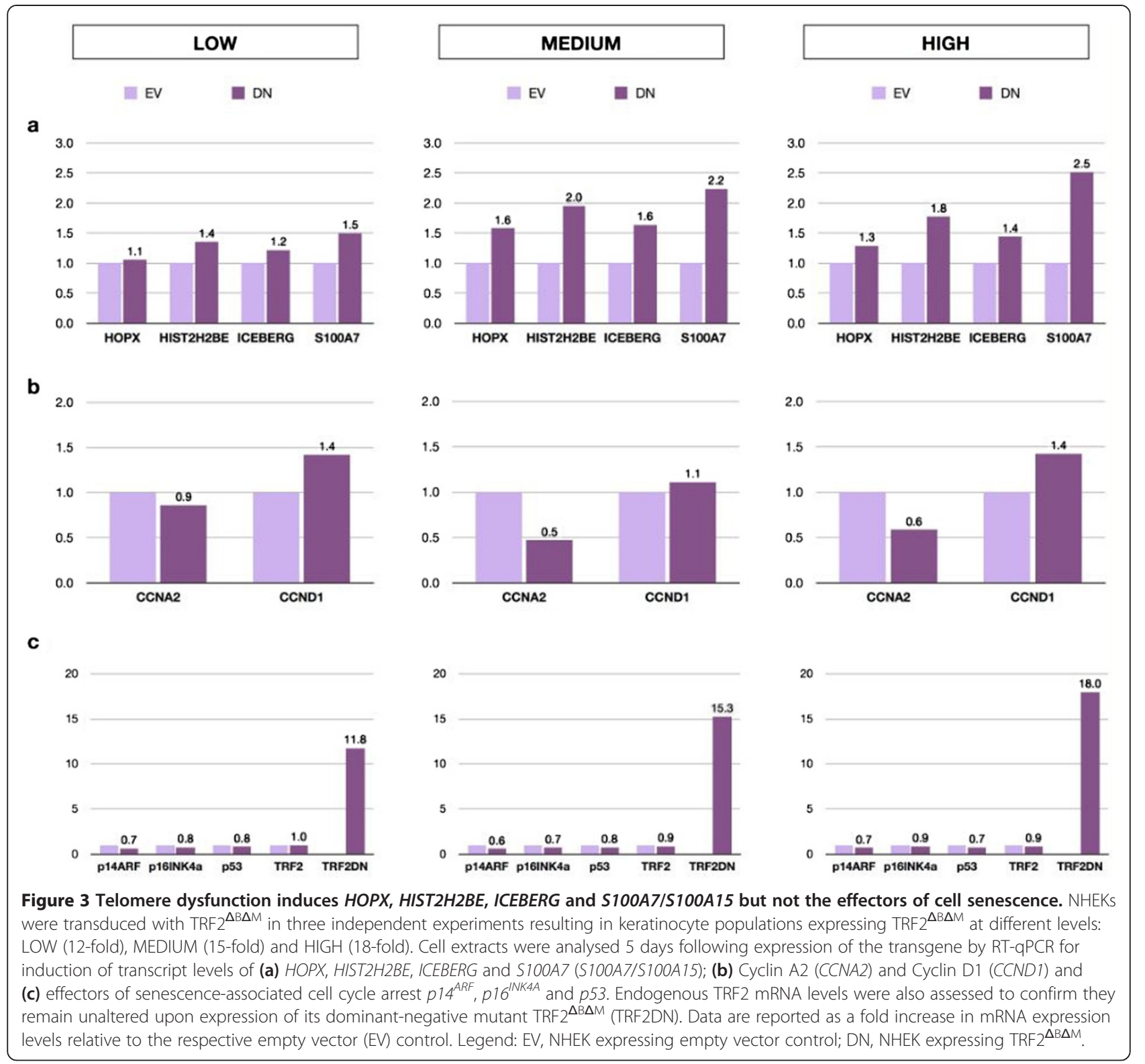

\section{Distinct response of S100A7 and S100A15 to telomere dysfunction and inducers of senescence}

During the course of this study, the highly homologous S100A15 (koebnerisin) was identified as part of the S100A7/S100A15 gene subfamily [35] and it became evident that the primers we had used to detect $\$ 100 A 7$ also detected the closely related S100A15 that, when expressed, shows a completely different expression pattern in squamous epithelia [35,36]. When specific primers were obtained and used to amplify each transcript separately, we observed that S100A7 mRNA levels were in general about 100-fold higher than S100A15 levels in keratinocytes (raw data not shown; presented data reported as a fold change relative to the relevant control) and their expression was distinct following induction of growth arrest by telomere uncapping and expression of the main senescence effectors. S100A7 (psoriasin) was indeed induced by telomere dysfunction but not by $\mathrm{p} 16^{\mathrm{INK} 4 \mathrm{~A}}, \mathrm{p} 14^{\mathrm{ARF}}$ or $\mathrm{p} 53$ (induced by 1.6 -fold with high levels of p53 but by 2.6 -fold with high levels of TRF2 $2^{\triangle B \Delta M}$-Figure 7a). In contrast, S100A15 (koebnerisin) was induced by the ectopic expression of $\mathrm{p} 16^{\mathrm{INK} 4 \mathrm{~A}}$ and $\mathrm{p} 53$ to a similar level to telomere uncapping and $\mathrm{p} 14^{\mathrm{ARF}}$ to a lesser extent (Figure 7a). Also, whilst S100A15 was only induced by MEDIUM/HIGH expression levels of $T R F 2^{\triangle B \Delta M}, S 100 A 7$ transcript was elevated even by a LOW expression of $T R F 2^{\triangle B \Delta M}$, i.e. to levels incapable of engaging permanent growth arrest. Thus, S100A7 seems to respond to even mild telomere 

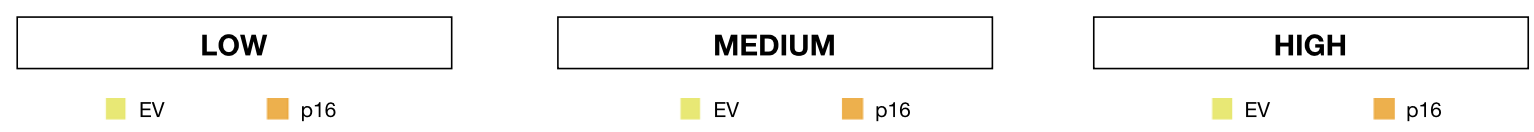

a
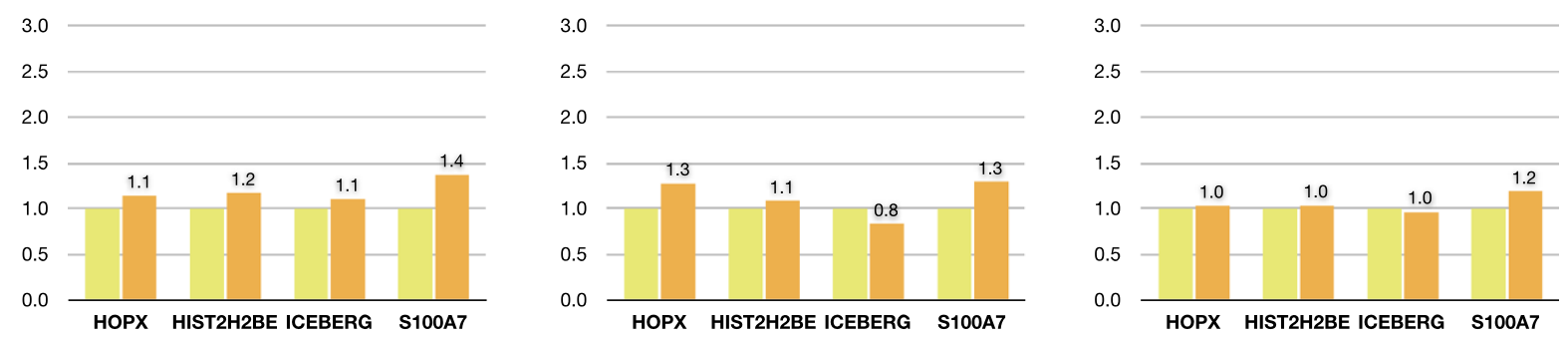

b
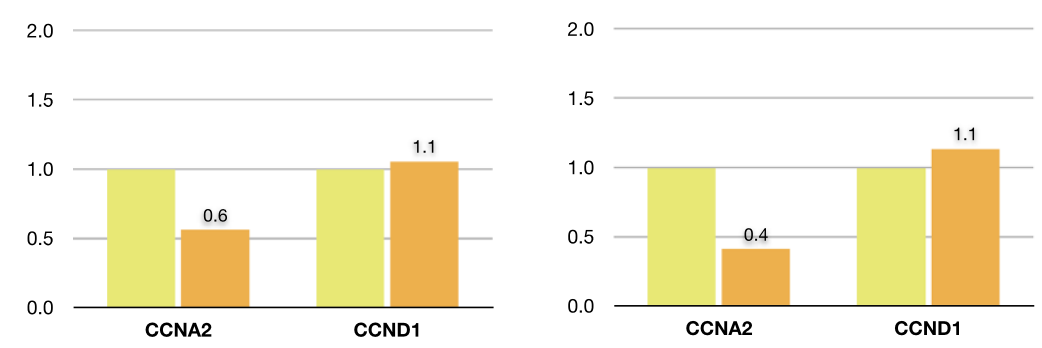

C
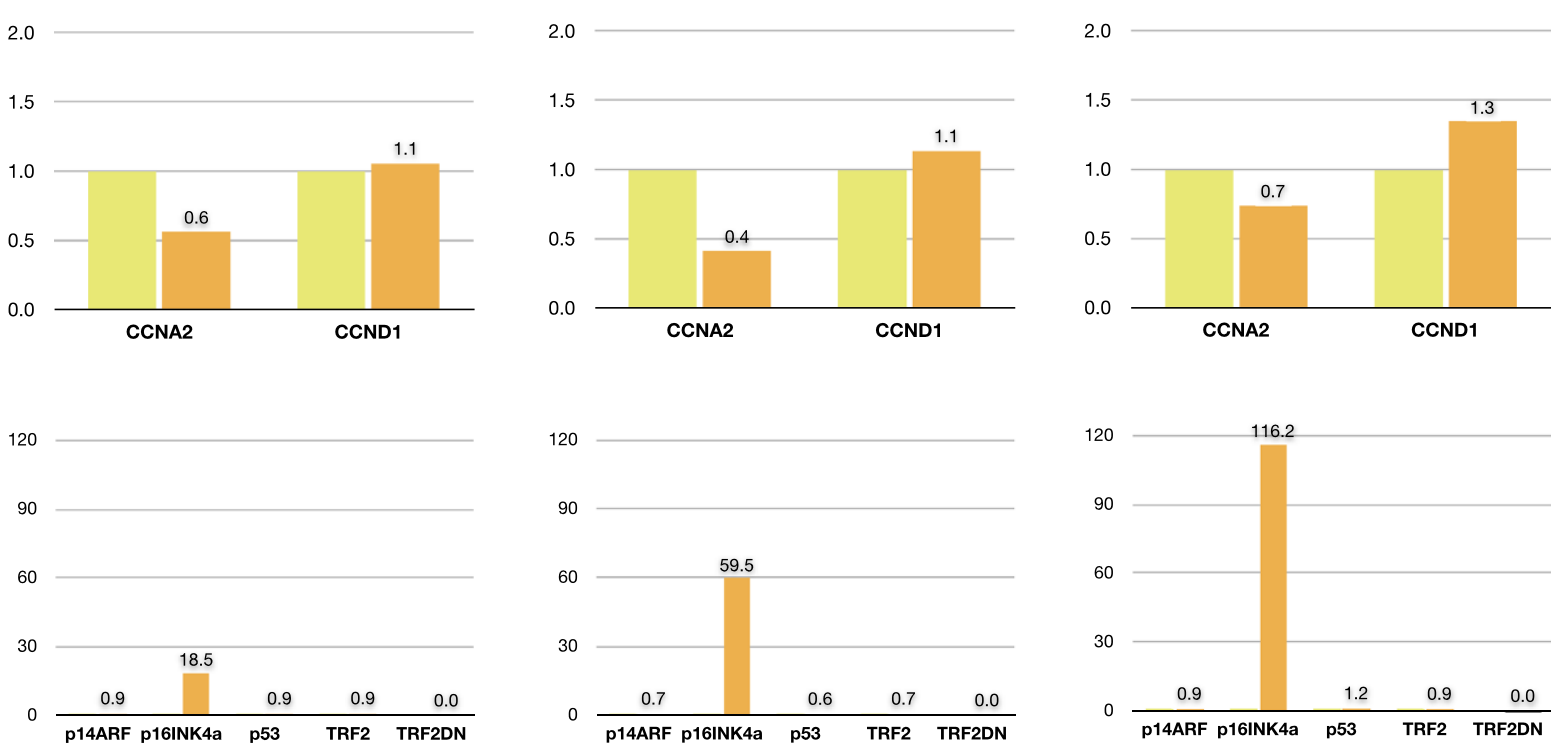

Figure 4 Transcriptional profile of populations of normal human epidermal keratinocytes expressing p16 ${ }^{\text {INK4A }}$. NHEKs were transduced with $p 16^{\mathrm{INK} 4 \mathrm{~A}}$ in three independent experiments resulting in keratinocyte populations expressing p16 $6^{\mathrm{INK} 4 \mathrm{~A}}$ at different levels: LOW (18-fold), MEDIUM (60-fold) and HIGH (116-fold). Cell extracts were analysed 5 days following expression of the transgene by RT-qPCR for induction of transcript levels of (a) HOPX, HIST2H2BE, ICEBERG and S100A7 (S100A7/S100A15); (b) Cyclin A2 (CCNA2) and Cyclin D1 (CCND1) and (c) effectors of senescence-associated cell cycle arrest $p 14^{A R F}, p 16^{I N K 4 A}$ and $p 53$. Data are reported as a fold increase in mRNA expression levels relative to the respective empty vector (EV) control. Legend: EV, NHEK expressing empty vector control; p16, NHEK expressing p16 ${ }^{\mathrm{INK} 4 \mathrm{~A}}$.

dysfunction, which suggests not only better specificity than S100A15 but also increased sensitivity to telomere damage. We also show that the elevation of either S100A7 or S100A15 was not merely a result of non-specific growth arrest since neither transcript was induced by repairable (Figure 7b) nor irreparable (Figure 7c) DNA double strand breaks. These results suggest that whilst the early increase in S100A7 expression could be a specific consequence of telomere dysfunction in keratinocytes, the increase in S100A15 expression may be a more general consequence of permanent growth arrest.

We previously reported that inducing telomere dysfunction in newborn human keratinocytes induced growth arrest and increased the expression of several genes,
HIST2H2BE, ICEBERG, HOPX and S10OA7, within 5 days, despite eliciting a very weak DDR that is typical of most cell types [28]. HIST2H2BE, ICEBERG, HOPX and S100A7 were also expressed when a p16 ${ }^{\mathrm{INK} 4 \mathrm{~A}}$-deficient dysplasia line (D17) underwent replicative senescence and telomere shortening in the absence of a strong DDR, and these four transcripts were shown to be reduced upon the ectopic expression of the catalytic component of telomerase, telomere lengthening and elimination of the weak DDR [28].

The above experiments suggested that the four candidate genes HIST2H2BE, ICEBERG, HOPX and S100A7 could be highly specific and early markers of keratinocyte telomere dysfunction, but several questions remained 


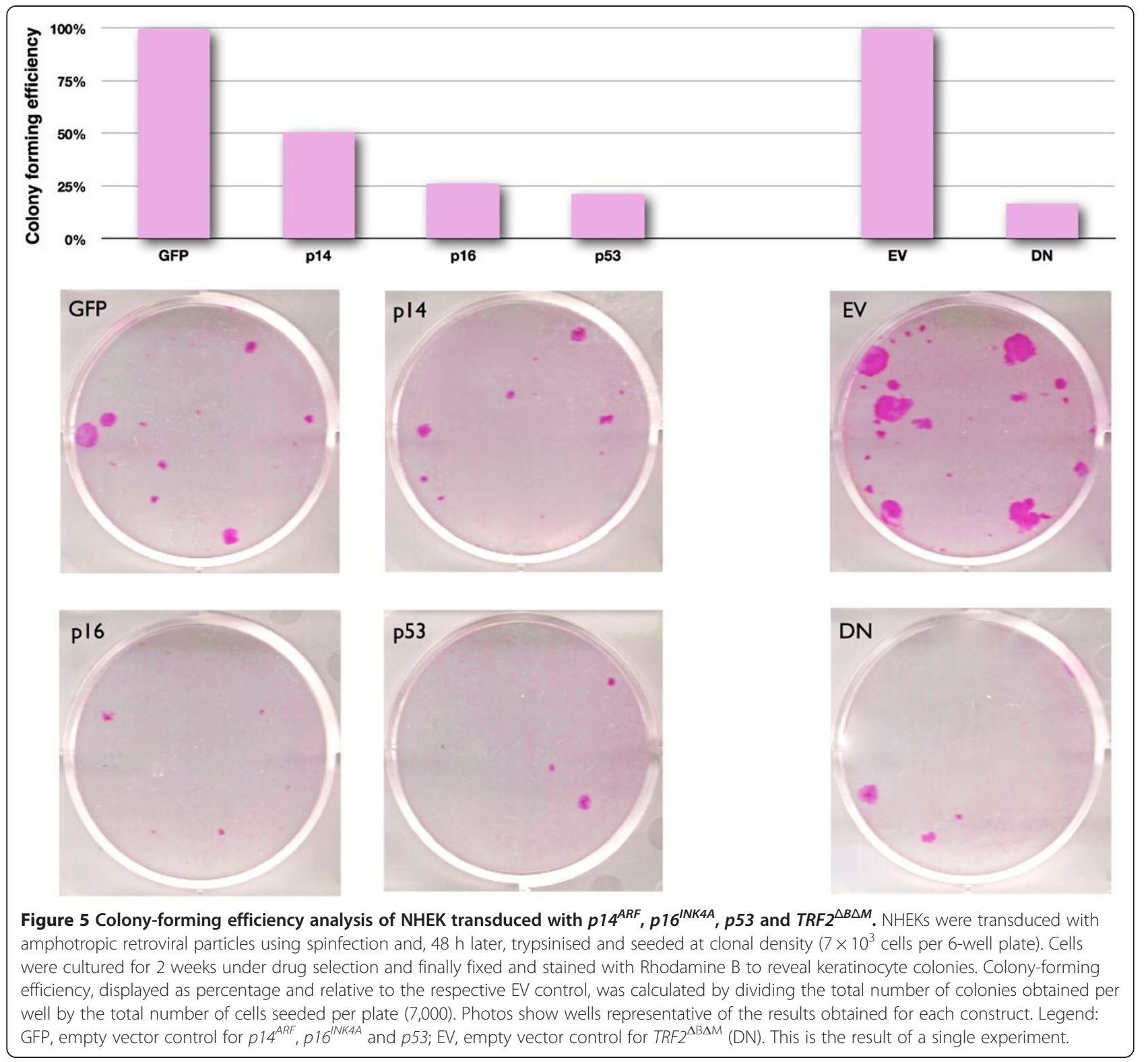

unanswered. For instance, it was possible that keratinocytes were unusually sensitive to the DDR, and that the weak DDR we observed was enough to induce the transcription of HIST2H2BE, ICEBERG, HOPX and S100A7. To test this, we subjected keratinocytes to both a low dose ( 2 gray) of $\gamma$ irradiation that had been calculated to simulate the uncapping of 92 telomeres, and higher doses (10 or 20 gray) that had been reported to induce human cellular senescence and a strong DDR [28]. However, only HIST $2 H 2 B E$ was shown to be induced by $\gamma$ irradiation. This is consistent with recent reports showing that chromatin components, such as $\mathrm{H} 2 \mathrm{~A}$ and $\mathrm{H} 2 \mathrm{~B}$ histones, are actively involved in the response to DNA damage $[37,38]$. $H I S T 2 H 2 B E$ is thus an active participant in the DDR and not a specific marker of telomere dysfunction-induced keratinocyte permanent growth arrest. In contrast, ICE$B E R G, H O P X$ and S100A7 were not induced even by a strong DDR or indeed permanent growth arrest.

To further test the specificity of ICEBERG, HOPX and $S 100 A 7$ to telomere dysfunction, we induced permanent growth arrest in a different way: by the ectopic expression of the transcripts encoding the cell cycle inhibitors $\mathrm{p} 14^{\mathrm{ARF}}, \mathrm{p} 16^{\mathrm{INK} 4 \mathrm{~A}}$ and $\mathrm{p} 53$. This experiment had the dual purpose of testing the specificity of the above genes and also whether the cell cycle effectors were sufficient to induce them. The expression of p53 and p14 ${ }^{\mathrm{ARF}}$ did induce ICEBERG expression, although the effect of p53 was highly variable, and p53 induced $H O P X$. The result 


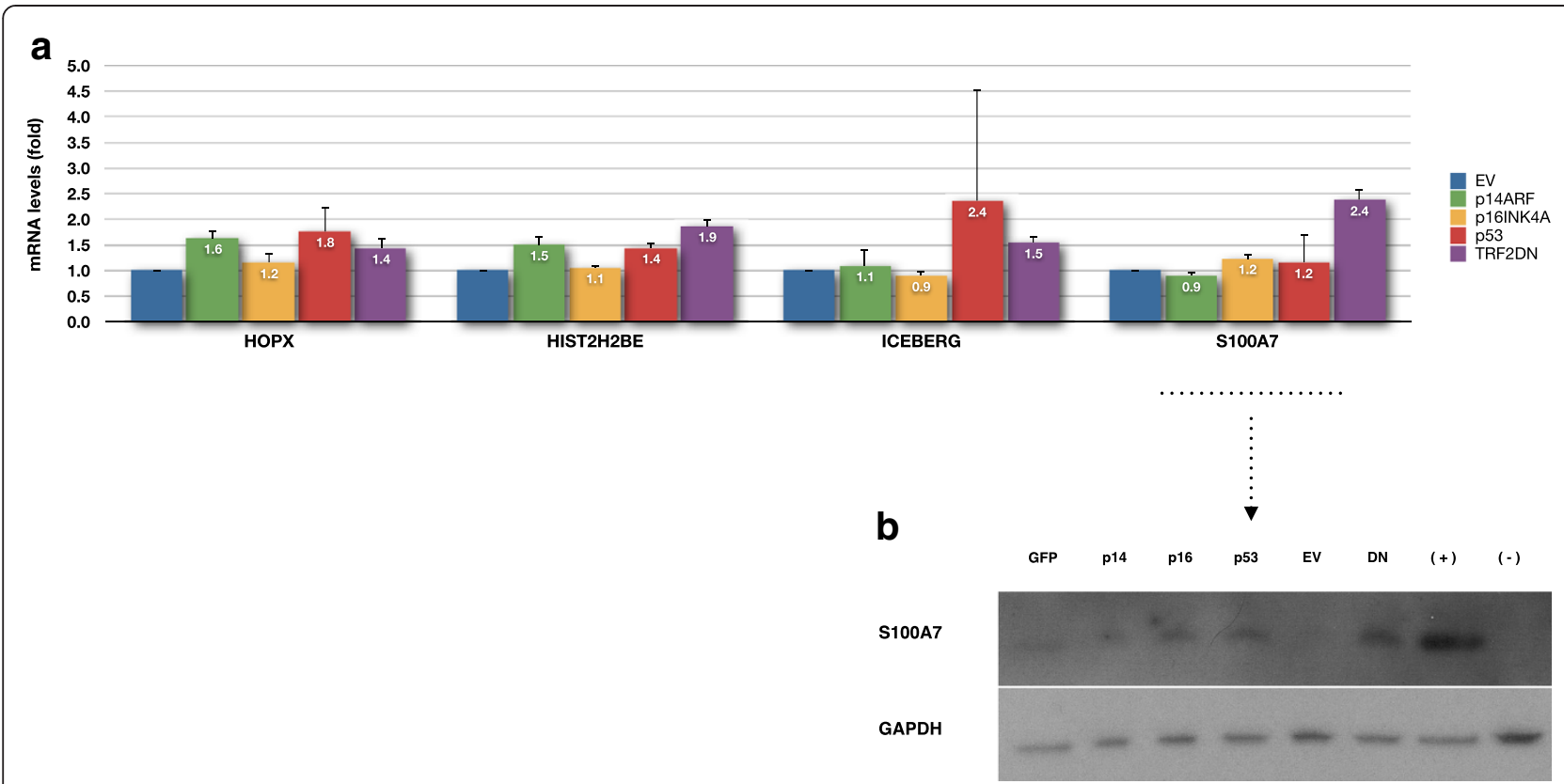

Figure 6 HOPX, HIST2H2BE, ICEBERG and S100A7/S100A15 transcripts in keratinocytes transduced with $p 14^{A R F}, p 16^{I N K 4 A}, p 53$ and

TRF2 $^{\mathbf{A B A M}}$. (a) Candidate markers HOPX, HIST2H2BE, ICEBERG and S100A7 (S100A7/S100A15) expression levels reported as a fold change in transcript relative to the respective empty vector (EV) control. Data are mean $\pm s d$ for two independent experiments $(n=2)$ corresponding to NHEK populations expressing MEDIUM and HIGH levels of the transgenes $p 14^{A R F}, p 16^{I N K 4 A}, p 53$ and TRF2 ${ }^{\triangle B \Delta M}$. (b) Representative blot of S100A7 protein levels for the same NHEK populations. Legend: GFP, NHEK expressing pBabe-GFP empty vector; p14, NHEK expressing pBabe-p14 ARF; p16, NHEK expressing pBabe-p16 $6^{\text {INK4a; }}$ p53, NHEK expressing pBabe-p53; EV, NHEK expressing pLPC empty vector; DN, NHEK expressing pLPC-TRF2 ${ }^{\triangle B \Delta M}$; (+) symbol, positive control (terminally differentiated NHEK); (-) symbol, negative control (telomerase-positive SCC-25 cell line).

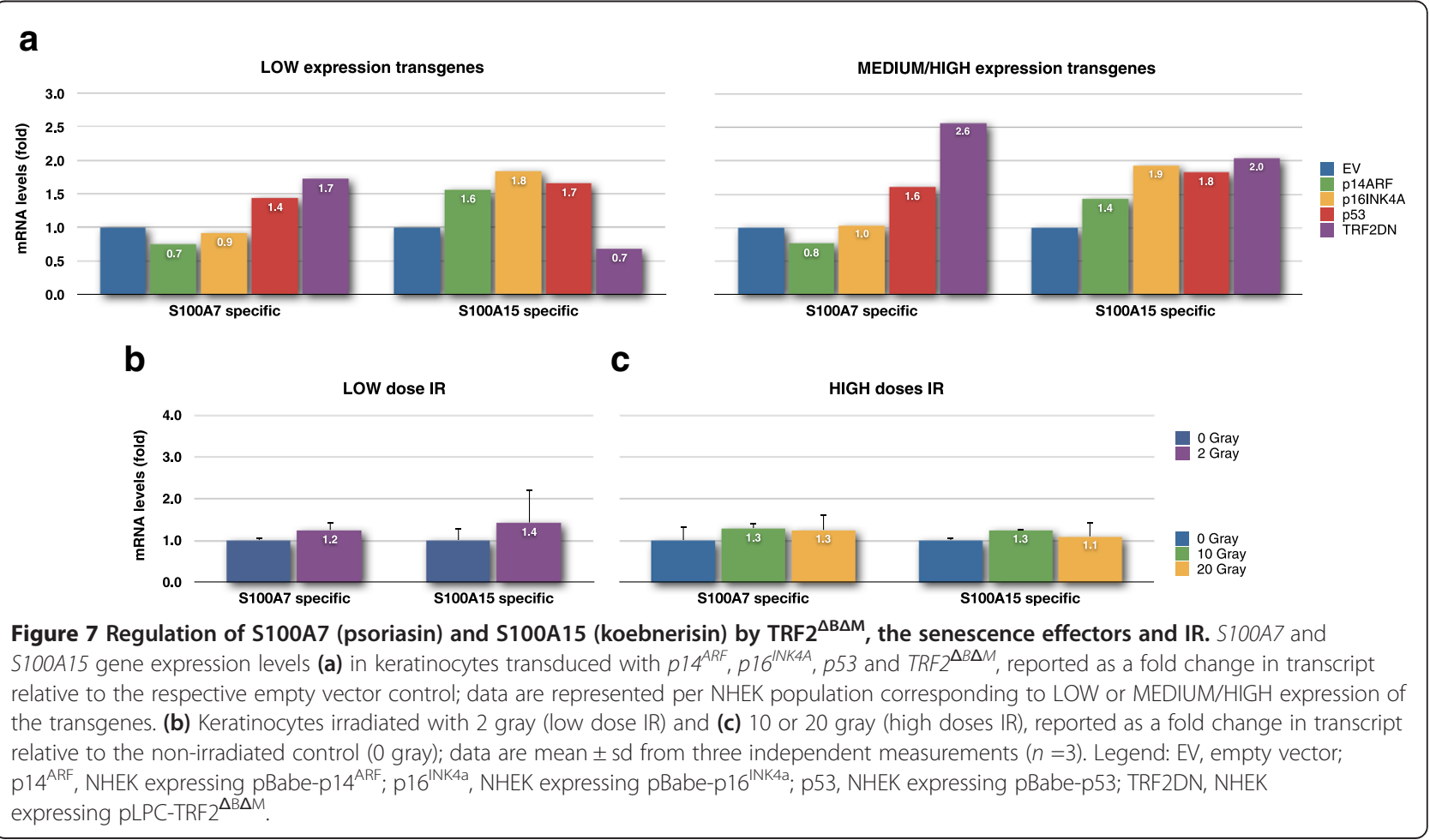


with p53 is a little difficult to reconcile with the absence of the induction of ICEBERG and HOPX following $\gamma$ irradiation, but we have consistently failed to observe a large increase in total p53 protein in human keratinocytes following $\gamma$ irradiation or telomere dysfunction and so the induction of ICEBERG and HOPX by p53 may be limited to situations such as UV exposure where p53 is stabilised and strongly over-expressed in human keratinocytes [39].

However, no transgene, except $T R F 2^{\triangle B \Delta M}$, induced S100A7 expression, and for this reason, we pursued S100A7 as a potential early biomarker of telomere dysfunction in the absence of DNA double strand breaks. This result is also similar to that obtained for several SASP proteins, which are also not induced by the ectopic expression of the cell cycle regulator and effector of senescence, p16 ${ }^{\mathrm{INK} 4 \mathrm{~A}}$ [40]. S100A7 was over-expressed both at the transcript and protein level following telomere uncapping by ectopic expression of TRF2 $2^{\triangle B \Delta M}$.

TRF2 has been reported to be over-expressed in both basal and squamous cell carcinomas of the skin [41] and very recently has been shown to regulate the recruitment of natural killer cells by a cell extrinsic mechanism [42]. However, our earlier work showed that whilst the over-expression of TRF2 at high levels did cause keratinocyte growth arrest it induced a distinct gene expression profile from $T R F 2^{\triangle B \Delta M}$ that did not include S100A7 (Minty et al., unpublished data). These data argue against our results being the consequence of TRF2 overexpression as opposed to telomere uncapping.

During the course of the study, we became aware that the primers used to detect S100A7 (psoriasin) also detected a closely related gene S100A15 (koebnerisin). Koebnerisin, unlike psoriasin, is expressed in the epidermal basal layer and in cell types other than keratinocytes. However, when we used specific primers for S100A7 and S100A15 transcripts, we found that the major $S 100$ transcript specifically induced by telomere dysfunction was S100A7 and that the expression of S100A15 was very low. However, interestingly S100A15 did seem to also be induced by the ectopic expression of $\mathrm{p} 16^{\mathrm{INK} 4 \mathrm{~A}}$ and $\mathrm{p} 53$; $\mathrm{p} 16^{\mathrm{INK} 4 \mathrm{~A}}$ is over-expressed in senescent keratinocytes in vitro [43] and increases in the epidermis of elderly humans $[25,26]$ where it is also inversely associated with long-lived families [26] and it will be interesting to test whether S100A15 follows a similar expression pattern to $\mathrm{p} 16^{\mathrm{INK} 4 \mathrm{~A}}$ in the epidermis of elderly subjects.

S100 proteins can participate in the squamous epithelial barrier as part of the cornified envelope, and S100A15 (koebnerisin) and S100A7 (psoriasin) both attracted interest because of their association with psoriasis. When released into the extracellular space, they synergise to participate in the innate immune response by acting as antimicrobial agents and by acting as chemoattractants for auxiliary immune cells and act as pro-inflammatory cytokines to amplify the immune response [44]. In normal skin, S100A7 (psoriasin) and S100A15 (koebnerisin) are both expressed by terminally differentiated keratinocytes of the upper epidermis, which are not replicative [36]. In contrast to psoriasin, koebnerisin is also produced by most cells in the basal epidermal layer, which might reflect the fact that most of the basal keratinocytes are non-dividing. Thus, koebnerisin could be a negative marker of replicating epidermal stem cells in the skin, which requires further investigation.

S100A7 (psoriasin) is upregulated in the early stages of tumour progression, where in its cytoplasmic form it has been reported to inhibit beta catenin signalling and act as a tumour suppressor in both breast epithelial cells [45] and keratinocytes [46]. S100A7 is downregulated when premalignant keratinocytes bypass senescence and is downregulated in the invasive parts of tumours in vivo. In contrast, in its secreted form, S100A7 binds to the receptor of advanced glycation endproducts (RAGE) on neighbouring tumour cells and can activate nuclear factor kappa B [47] and hence possibly members of the SASP [48] in neighbouring cells, including matrix metalloproteinases [49] and a variety of cytokines and other molecules [1]. Thus, S100A7 may mediate the effects of telomere dysfunction by first acting as a tumour suppressor intracellularly but may also act as a keratinocyte-specific SASP protein that can also spread its effects to neighbouring cells and as such may modulate to both ageing and tumour progression.

S100A7 protein is also detectable in human serum and as such might turn out to have potential as a noninvasive marker of keratinocyte telomere dysfunction in human ageing and disease. Indeed, serum S100A7 protein levels have been reported to be associated with squamous and large cell carcinomas of the lung in a cell type-specific manner [29]. The association of S100A7 protein with squamous cell carcinoma is something of a paradox as these cancers would very likely have deregulated telomerase [16] and reduced telomere dysfunction [50] in the immortal cells of the tumour. Furthermore, we have previously reported that the ectopic expression of telomerase in $\mathrm{p} 16^{\mathrm{INK} 4 \mathrm{~A}}$-deficient dysplastic keratinocytes can reverse the upregulation of $S 100 A 7$ following telomere attrition and senescence [28]; also, many telomerase-positive immortal keratinocyte lines have reduced levels of S100A7 transcript (Hunter, Thurlow and Parkinson - unpublished data). However, significant levels of anaphase bridges and very short average telomere lengths have been reported in many human cancers, including squamous cell carcinomas [50,51], suggesting that considerable telomere dysfunction exists in portions of these telomerase-positive tumours. 
At present, we can only speculate on the mechanism by which telomere uncapping upregulates S100A7, but recent data has suggested that the $\mathrm{S} 100$ proteins can be positively regulated by the histone demethylase JMJD3 in foetal human keratinocytes by repressing the H3K27me3 marks [52], and the histone demethylase LSD1 is required for estrogen-dependent S100A7 gene expression in human breast cancer cells [53]. Interestingly, telomere shortening and uncapping in telomerase-deficient mice also downregulates H3K27me3 and globally derepresses the genome [54], and therefore, the regulation of chromatin by telomere uncapping may offer a potential explanation for our results and the observation that telomerase can affect organismal ageing and healthspan when targeted only to epithelia as secreted proteins from cells with short telomeres could influence other organs in a paracrine manner [55].

\section{Conclusions}

In summary, we have shown here that several gene transcripts (ICEBERG, HOPX, S100A7 and S100A15) are upregulated following telomere uncapping in human keratinocytes independently of the DDR, and in the case of $S 100 A 7$, this was also independent of cell cycle effectors such as $\mathrm{p} 16^{\mathrm{INK} 4 \mathrm{~A}}$, suggesting that the secreted form of S100A7 is a keratinocyte-specific SASP with the potential to non-invasively detect keratinocytes with dysfunctional telomeres.

\section{Methods}

\section{Cell culture}

Normal human epidermal keratinocytes, strain NHEK-131 (GIBCO-Invitrogen, Paisley, UK), were derived from a pool of a minimum of three neonatal foreskins and obtained at 6.8 mean population doublings (MPDs). Keratinocytes were cultured at $37^{\circ} \mathrm{C}$ in a $10 \% \mathrm{CO}_{2} / 90 \%$ air with lethally irradiated 3T3 feeder cells in flavin-adenine enriched medium $\left(\mathrm{FAD}^{-}\right.$). FAD $^{-}$consists of 3 parts DMEM $4.5 \mathrm{~g} / \mathrm{L}$ glucose (Lonza, Slough, UK), 1 part Ham's F12 (Lonza), 10\% ( $v / v)$ Hyclone Fetalclone II serum (Fisher Scientific, Loughborough, UK), $20 \mathrm{mM}$ HEPES buffer (Lonza), $100 \mathrm{U} / \mathrm{ml}$ penicillin, $100 \mathrm{U} / \mathrm{ml}$ streptomycin (Lonza) and $2 \mathrm{mM}$ L-Glutamine (Lonza), supplemented with $1.8 \times 10^{-4} \mathrm{M}$ Adenine (Sigma-Aldrich, Poole, Dorset, UK), $5 \mu \mathrm{g} / \mathrm{ml}$ insulin (Sigma-Aldrich), $5 \mu \mathrm{g} / \mathrm{ml}$ transferrin (Sigma-Aldrich), $0.4 \mu \mathrm{g} / \mathrm{ml}$ hydrocortisone (Sigma-Aldrich) and $8.4 \mathrm{ng} / \mathrm{ml}$ cholera toxin (Fisher Scientific, Loughborough, UK). Medium was replenished every third or fourth day with $\mathrm{FAD}^{+}$complete medium, which consists of $\mathrm{FAD}^{-}$supplemented with $10 \mathrm{ng} / \mathrm{ml}$ of epidermal growth factor (Sigma-Aldrich).

\section{Irradiation}

Cells were irradiated using a GSR D1 Cs-137 low doserate gamma irradiator (GSM, Leipzig, Germany) at 1.493 gray/min for $1 \mathrm{~min} 20 \mathrm{~s}$ for a total dose of 2 gray with a recovery period of $6 \mathrm{~h}$ or at $1.493 \mathrm{gray} / \mathrm{min}$ for $13 \mathrm{~min}$ $23 \mathrm{~s}$ for a total dose of 20 gray and 0.747 gray/min for $13 \mathrm{~min} 23 \mathrm{~s}$ for a total dose of 10 gray, both with a recovery period of 5 days.

\section{Retroviral transduction}

Retroviral vectors pLPC-N MYC (12540 Addgene, Cambridge, MA.) and pLPC-NMYC TRF2 ${ }^{\triangle \mathrm{B} \Delta \mathrm{M}}$ (16069 Addgene) were donated by Titia de Lange (Rockefeller University, NYC, USA); pBABE-puro p14 ${ }^{\mathrm{ARF}}$, pBABE-puro p $16^{\mathrm{INK} 4 \mathrm{a}}$ and pBABE-puro p53 were donated by Gordon Peters (London Research Institute, CRUK, London, UK); and pBABEpuro GFP was donated by Cleo Bishop (Blizard Institute, QMUL, London, UK). Vector DNA was amplified in XL1Blue Competent Cells (Stratagene, La Jolla, CA, USA) and purified with the Plasmid DNA purification Maxi kit (Qiagen, Manchester, UK) according to manufacturer's instructions. Retroviral supernatants were produced by transfecting plasmid DNA into Phoenix A packaging cells (Nolan Labs, Stanford, USA) using FuGENE ${ }^{\circledR} 6$ transfection reagent (Roche) at a $1 \mu \mathrm{g}$ DNA to $2.5 \mu \mathrm{l}$ FuGENE 6 ratio. Next, amphotropic supernatants were used to infect keratinocytes (after removing feeders) with two consecutive rounds of centrifugation at $300 \mathrm{rpm}$ for $1 \mathrm{~h}$ at $32^{\circ} \mathrm{C}$ (spinfection), $6 \mathrm{~h}$ apart, in the presence of $5 \mathrm{ug} / \mathrm{ml}$ polybrene (Sigma-Aldrich) to facilitate viral uptake. Retroviral supernatant was replaced with FAD medium and transduced keratinocytes were kept under normal culture conditions in the presence of irradiated 3T3 'feeders'. Mock-transduced plates were treated with polybrene only. Puromycin (Sigma-Aldrich) selection $(1 \mu \mathrm{g} / \mathrm{ml})$ was introduced $24 \mathrm{~h}$ later and kept for $72 \mathrm{~h}$ following the 24-h period allowed for gene expression at which point the mock plates were dead. Selective medium was then replaced with FAD overnight and cell pellets collected by centrifugation.

\section{qPCR}

Extraction of total RNA was performed using the RNeasy Mini Kit (Qiagen) according to manufacturer's instructions, including sample homogenisation with QIAshredder (Qiagen) and DNase treatment with the RNase-free DNase Set (Qiagen). Purified RNA was reverse transcribed using with Finnzymes DyNAmo ${ }^{\text {тм }}$ cDNA Synthesis Kit (New England BioLabs, Hitchin, UK) and the cDNA stored at $-20^{\circ} \mathrm{C}$. RT quantitative real-time PCR (absolute copy number quantification using standard curve for each gene) was performed using $\mathrm{SYBR}^{\curvearrowleft}$ green I Master (hot-start Taq polymerase master mix) in the LightCycler $480^{\circ}$ qPCR system (Roche Applied Science, Welwyn Garden City, Herts., UK). Target gene relative expression levels were calculated in relation to keratinocyte reference genes $P O L R 2 A$ and YAP1 [56] using the LightCycler $480^{\circ}$ 
Relative Quantification Software (with built-in multiple reference genes normalisation algorithm).

Primers used were, CCNA2 fwd CCATACCTCAAGTA TTTGCCATC and CCNA2 rev TCCAGTCTTTCGTATT AATGATTCAG for CCNA2 cyclin A2 [GenBank: NM_ 001237.3]; CCND1 fwd CGTGGCCTCTAAGATGAAGG and CCND1 rev GTGTTCAATGAAATCGTGCG for CCND1 cyclin D1 [GenBank: NM_053056.2]; HIST2H2BE fwd GGTAGATCCACCCTTATGCTT and HIST2H2BE rev TTAAGAGGGGAACACCATGAG for HIST2H2BE histone cluster 2, H2be [GenBank: NM_003528.2]; HOPX fwd ACTTCAACAAGGTCGACAAGC and HOPX rev GG GTCTCCTCCTCGGAAA for HOPX HOP homeobox [GenBank: NM_139212.3; GenBank: NM_032495.5; GenBank: NM_001145460.1; GenBank: NM_001145 459.1; GenBank: NM_139211.4]; ICEBERG fwd CTTG CTGGATTGCCTATTAGAG and ICEBERG rev TTGA GGGTCTTCTTCACAGAG for CARD18 caspase recruitment domain family, member 18 [GenBank: NM 021571.2]; IVL fwd TGCCTGAGCAAGAATGTGAG and IVL rev TTCCTCATGCTGTTCCCAGT for IVL involucrin [GenBank: NM_005547.2]; p14 ${ }^{\mathrm{ARF}}$ fwd CTA CTGAGGAGCCAGCGTCTA and $14^{\mathrm{ARF}}$ rev CTGCC CATCATCATGACCT for CDKN2A cyclin-dependent kinase inhibitor 2A, variant 4 or beta [GenBank: NM_ 058195.2]; p16 ${ }^{\mathrm{INK} 4 \mathrm{~A}}$ fwd CCAACGCACCGAATAGT TACG and $\mathrm{p} 16^{\mathrm{INK} 4 \mathrm{~A}}$ rev GCGCTGCCCATCATCATG for $C D K N 2 A$ cyclin-dependent kinase inhibitor 2A, variant 1 or alpha [GenBank: NM_000077.3]; p21 ${ }^{\text {WAF1 }}$ fwd TCACTGTCTTGTACCCTTGTGC and p21 ${ }^{\text {WAF1 }}$ rev GGCGTTTGGAGTGGTAGAAA for CDKN1A cyclindependent kinase inhibitor 1A [GenBank: NM_000389.3; GenBank: NM_078467.1]; p53 fwd AGGCCTTGGAACT CAAGGAT and p53 rev CCCTTTTTGGACTTCAGGTG for TP53 tumour protein p53 [GenBank: NM_000546.4; GenBank: NM_001126114.4; GenBank: NM_0011261 13.1; GenBank: NM_001126112.1; GenBank: NM_001 126115.1; GenBank: NM_001126116.1; GenBank: NM_ 001126117.1]; POLR2A fwd GCAAATTCACCAAGA GAGACG and POLR2A rev CACGTCGACAGGAAC ATCAG for POLR2A polymerase (RNA) II (DNA directed) polypeptide A [GenBank: NM_000937.3]; S100A7 fwd AGACGTGATGACAAGATTGAC and S100A7 rev TGTCTTTTTTCTCAAAGACGTC for S100A7 S100 calcium-binding protein A7 [GenBank: NM_002963.3]; S100A15 fwd ACGTCACTCCTGTCTCTCTTTACT and S100A15 rev TGATGAATCAACCCATTTCCTGGG for S100A7A S100 calcium-binding protein A7A [GenBank: NM_176823.3]; and S100A7/S100A15 fwd AAAGCA AAGATGAGCAACAC and S100A7/S100A15 rev AA GTTCTCCTTCATCATCGTC for co-amplification of both; TRF2 fwd CCAGATGAAGACAGTACAACCAA and TRF2 rev CCAGTTTCCTTCCCCATATTT for TERF2 telomeric repeat binding factor 2 [GenBank: NM_005652.2];
TRF2DN fwd GTTGATTTCTGAAGAAGATTTGTT and TRF2DN rev GTGGAAGTAGAACTTGAGCAC for $T R F 2^{\triangle B \Delta M}$; YAP1 fwd CCCAGATGAACGTCACAGC and YAP1 rev GATTCTCTGGTTCATGGCTGA for YAP1 Yes-associated protein 1 [GenBank: NM_000389.3; GenBank: NM_078467.1]. S100A7/S100A15 primers [28] amplify highly homologous transcripts for $S 100 A 7$ (psoriasin) and S100A15 (koebnerisin). S100A7-specific and S100A15specific primers were designed to independently quantify each transcript [57]. HOPX primers were designed to amplify all five transcript variants described for this gene. The design of a specific primer set for amplification of exogenous TRF2 $2^{\triangle B \Delta M}$ was performed manually, the forward sequence directed at the myc tag (located upstream of the gene insert) and the reverse sequence targeting the $T R F 2^{\triangle B \Delta M}$ transgene in the retroviral construct. We have validated that all primer pairs are highly specific for the expected product without cross-amplification. All qPCR results were repeated as three complete experiments with two to three replicates each unless otherwise stated.

\section{Western blotting}

Cells were lysed with M-PER $^{\bullet}$ Mammalian Protein Extraction Reagent (Thermo Scientific) and cOmplete Mini EDTA-free protease inhibitor cocktail tablets (Roche). Mixture was gently shaken for $10 \mathrm{~min}$ at room temperature and cell debris removed by centrifugation at $14,000 \mathrm{~g}$ for $15 \mathrm{~min}$. Supernatant was collected and kept on ice before being stored at $-80^{\circ} \mathrm{C}$. Protein concentration in the cell lysates was measured using the $\mathrm{DC}^{\mathrm{T}}$ Protein Assay (BioRad, Hertfordshire, UK). Protein samples for Western blotting were prepared by adding 1x NuPAGE ${ }^{\oplus}$ LDS Sample Buffer (Life Technologies) followed by denaturation for $5 \mathrm{~min}$ at $100^{\circ} \mathrm{C}$. Proteins were loaded onto NuPAGE ${ }^{\oplus} 10 \%$ Bis-Tris precast resolving gels (Invitrogen) and separated by gel electrophoresis at $130 \mathrm{~V}$ on $1 \mathrm{x}$ NuPAGE ${ }^{\oplus}$ running buffer (Invitrogen). Transfer to Immobilon ${ }^{\mathrm{TM}}$ PVDF membranes (Millipore, Watford, UK) was performed on transfer buffer (25 mM Tris, $190 \mathrm{mM}$ glycine and 20\% methanol) at $30 \mathrm{~V}$ for $90 \mathrm{~min}$ at $4^{\circ} \mathrm{C}$. Membranes were blocked in 5\% non-fat milk in Tris-buffered saline/

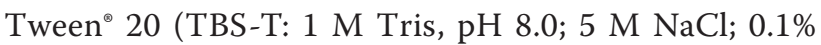
Tween $^{\oplus} 20$ ) for $1 \mathrm{~h}$ at room temperature. Next, membranes were probed with primary antibodies in $5 \%$ non-fat milk in TBS-T overnight at $4^{\circ} \mathrm{C}$ followed by incubation with HRP-conjugated secondary antibodies, prepared in 5\% non-fat milk in TBS-T, for $1 \mathrm{~h}$ at room temperature. Immunodetection was performed with Amersham $^{\mathrm{Tm}}$ ECL Plus chemiluminescent detection system (GE Healthcare Life Sciences) and visualised on Amersham $^{\text {TM }}$ ECL Hyperfilm (GE Healthcare Life Sciences, Chalfont St. Giles, Bucks, UK). Primary antibodies used were mouse monoclonal anti-human p21 WAF1 $($ C70) at 
1:250 dilution (610233 BD Transduction Labs), mouse monoclonal anti-human p53 (DO-1) at 1:250 dilution (sc-126 Santa Cruz Biotechnology, CA), mouse monoclonal anti-human psoriasin/HID5/S100A7 at 1:1,000 dilution (IMG-409A Imgenex, San Diego, CA) and rabbit polyclonal anti-human GAPDH at 1:1,000 dilution (ab9485 Abcam Cambridge, UK). Secondary antibodies used were polyclonal goat anti-mouse IgG HRP-conjugated at 1:2,500 dilution (Fisher Scientific) and polyclonal goat anti-rabbit IgG HRP-conjugated at 1:2,500 dilution (Fisher Scientific).

In the UK commercially derived human cells are not subject to further ethical approval by the purchaser and once passaged they are regarded as a cell line and exempt.

\section{Additional files}

Additional file 1: Figure S1. Transcriptional profile of populations of normal human epidermal keratinocytes expressing p14.ARF. NHEKs were transduced with p14 $4^{\mathrm{ARF}}$ in three independent experiments resulting in keratinocyte populations expressing p14.ARF at different levels: LOW (89-fold), MEDIUM (142-fold) and HIGH (220-fold). Cell extracts were analysed 5 days following expression of the transgene by RT-qPCR for induction of transcript levels of (a) HOPX, HIST2H2BE, ICEBERG and S100A7 (S100A7/S100A15); (b) Cyclin A2 (CCNA2) and Cyclin D1 (CCND1) and (c) effectors of senescence-associated cell cycle arrest $p 14^{A R F}, p 16^{I N K 4 A}$ and $p 53$. Data are reported as fold increase in mRNA expression levels relative to the respective empty vector (EV) control. Legend: EV, NHEK expressing empty vector control; p14, NHEK expressing p14 ARF.

Additional file 2: Figure S2. Transcriptional profile of populations of normal human epidermal keratinocytes expressing p53. NHEKs were transduced with $p 53$ in three independent experiments resulting in keratinocyte populations expressing p53 at different levels: LOW (10-fold), MEDIUM (7-fold) and HIGH (29-fold). Cell extracts were analysed 5 days following expression of the transgene by RT-qPCR for induction of transcript levels of (a) HOPX, HIST2H2BE, ICEBERG and S100A7 (S100A7) S100A15); (b) Cyclin A2 (CCNA2) and Cyclin D1 (CCND1) and (c) effectors of senescence-associated cell cycle arrest $p 14^{A R F}, p 16^{\text {INKAA }}$ and $p 53$. Data are reported as fold increase in mRNA expression levels relative to the respective empty vector (EV) control. Legend: EV, NHEK expressing empty vector control; p53, NHEK expressing p53.

\section{Abbreviations}

DDR: DNA damage response; DMEM: Dulbecco's modified Eagle's medium; DSB: DNA double strand break; FAD: flavin-adenine enriched medium; GAPDH: glyceraldehyde-3-phosphate dehydrogenase; HRP: horseradish peroxidase; irDSB: irreparable DNA double strand break; MPD: mean population doubling; NHEK: normal human epidermal keratinocyte; OSCC: oral squamous cell carcinoma; RS: replicative senescence; SASP: senescence-associated secretory phenotype; TRF2 or TERF2: telomeric repeat binding factor 2; TRF2DN or TRF $2^{\triangle \mathrm{B} \Delta \mathrm{M}}$ : dominant-negative TRF2 or TRF2 delta B delta $\mathrm{M}$.

\section{Competing interests}

The authors declare that they have no competing interests.

\section{Authors' contributions}

AC: study design, study execution, data preparation and writing of the manuscript. FM, EH, RW and EKP: study design and writing of the manuscript. All authors read and approved the final manuscript.

\section{Acknowledgements}

We wish to thank Titia de Lange, Gordon Peters and Cleo Bishop for the gifts of retroviral vectors. Alice de Castro was supported by a Research into Ageing (Age UK) PhD studentship.

\section{Author details}

'Centre for Clinical \& Diagnostic Oral Sciences, Institute of Dentistry, Barts and the London School of Medicine and Dentistry, Queen Mary University of London, Turner Street, London E1 2AD, UK. ${ }^{2}$ Department of Dermatology, Ludwig-Maximilian University Munich, Frauenlobstrasse 9-11, 80337 Munich, Germany. ${ }^{3}$ Blizard Building, 4, Newark Street, London E1 2AT, UK.

Received: 27 June 2014 Accepted: 3 October 2014

Published: 17 October 2014

\section{References}

1. Coppe JP, Patil CK, Rodier F, Sun Y, Munoz DP, Goldstein J, Nelson PS, Desprez PY, Campisi J: Senescence-associated secretory phenotypes reveal cell-nonautonomous functions of oncogenic RAS and the p53 tumor suppressor. PLOS Biol 2008, 6:2853-2868.

2. Kuilman T, Peeper DS: Senescence-messaging secretome: SMS-ing cellular stress. Nat Rev Cancer 2009, 9:81-94.

3. Jiang H, Schiffer E, Song Z, Wang J, Zurbig P, Thedieck K, Moes S, Bantel H, Saal N, Jantos J, Brecht M, Jeno P, Hall MN, Hager K, Manns MP, Hecker H, Ganser A, Dohner K, Bartke A, Meissner C, Mischak H, Ju Z, Rudolph KL: Proteins induced by telomere dysfunction and DNA damage represent biomarkers of human aging and disease. Proc Natl Acad Sci U S A 2008, 105:11299-11304.

4. Harley $C B$, Futcher $A B$, Greider $C W$ : Telomeres shorten during ageing of human fibroblasts. Nature 1990, 345:458-460.

5. De Lange T: How shelterin solves the telomere end-protection problem. Cold Spring Harb Symp Quant Biol 2010, 75:167-177.

6. De Lange T: Shelterin: the protein complex that shapes and safeguards human telomeres. Genes Dev 2005, 19:2100-2110.

7. Olovnikov AM: A theory of marginotomy. The incomplete copying of template margin in enzymic synthesis of polynucleotides and biological significance of the phenomenon. J Theor Biol 1973, 41:181-190.

8. Watson JD: Origin of concatemeric T7 DNA. Nat New Biol 1972, 239:197-201

9. Makarov VL, Hirose Y, Langmore JP: Long G tails at both ends of human chromosomes suggest a C strand degradation mechanism for telomere shortening. Cell 1997, 88:657-666.

10. Petersen S, Saretzki G, Von Zglinicki T: Preferential accumulation of single-stranded regions in telomeres of human fibroblasts. Exp Cell Res 1998, 239:152-160

11. Von Zglinicki T, Saretzki G, Docke W, Lotze C: Mild hyperoxia shortens telomeres and inhibits proliferation of fibroblasts: a model for senescence? Exp Cell Res 1995, 220:186-193.

12. Takai $H$, Smogorzewska A, De Lange T: DNA damage foci at dysfunctional telomeres. Curr Biol 2003, 13:1549-1556.

13. D'Adda Di Fagagna F, Reaper PM, Clay-Farrace L, Fiegler H, Carr P, Von Zglinicki T, Saretzki G, Carter NP, Jackson SP: A DNA damage checkpoint response in telomere-initiated senescence. Nature 2003, 426:194-198.

14. Fumagalli M, Rossiello F, Clerici M, Barozzi S, Cittaro D, Kaplunov JM, Bucci G, Dobreva M, Matti V, Beausejour CM, Herbig U, Longhese MP, D'Adda Di Fagagna F: Telomeric DNA damage is irreparable and causes persistent DNA-damage-response activation. Nat Cell Biol 2012, 14:355-365.

15. Hewitt G, Jurk D, Marques FD, Correia-Melo C, Hardy T, Gackowska A, Anderson R, Taschuk M, Mann J, Passos JF: Telomeres are favoured targets of a persistent DNA damage response in ageing and stress-induced senescence. Nat Commun 2012, 3:708.

16. Mao L, El-Naggar AK, Fan YH, Lee JS, Lippman SM, Kayser S, Lotan R, Hong WK: Telomerase activity in head and neck squamous cell carcinoma and adjacent tissues. Cancer Res 1996, 56:5600-5604.

17. Rheinwald JG, Hahn WC, Ramsey MR, Wu JY, Guo Z, Tsao H, De Luca M, Catricala C, OToole KM: A two-stage, p16(INK4A)- and p53-dependent keratinocyte senescence mechanism that limits replicative potential independent of telomere status. Mol Cell Biol 2002, 22:5157-5172.

18. Suram A, Kaplunov J, Patel PL, Ruan H, Cerutti A, Boccardi V, Fumagalli M, Di Micco R, Mirani N, Gurung RL, Hande MP, D'Adda Di Fagagna F, Herbig U: Oncogene-induced telomere dysfunction enforces cellular senescence in human cancer precursor lesions. EMBO J 2012, 31:2839-2851.

19. Giangreco A, Qin M, Pintar JE, Watt FM: Epidermal stem cells are retained in vivo throughout skin aging. Aging Cell 2008, 7:250-259.

20. Sharpless NE, DePinho RA: How stem cells age and why this makes us grow old. Nat Rev Mol Cell Biol 2007, 8:703-713. 
21. Barrandon $\mathrm{Y}$, Green $\mathrm{H}$ : Three clonal types of keratinocyte with different capacities for multiplication. Proc Natl Acad Sci U S A 1987, 84:2302-2306.

22. Lindsey J, McGill NI, Lindsey LA, Green DK, Cooke HJ: In vivo loss of telomeric repeats with age in humans. Mutat Res 1991, 256:45-48.

23. Nakamura K, Izumiyama-Shimomura N, Sawabe M, Arai T, Aoyagi Y, Fujiwara M, Tsuchiya E, Kobayashi Y, Kato M, Oshimura M, Sasajima K, Nakachi K, Takubo K: Comparative analysis of telomere lengths and erosion with age in human epidermis and lingual epithelium. J Invest Dermatol 2002, 119:1014-1019.

24. Sugimoto M, Yamashita R, Ueda M: Telomere length of the skin in association with chronological aging and photoaging. J Dermato/ Sci 2006, 43:43-47.

25. Ressler S, Bartkova J, Niederegger H, Bartek J, Scharffetter-Kochanek K, Jansen-Durr P, Wlaschek M: p16INK4A is a robust in vivo biomarker of cellular aging in human skin. Aging Cell 2006, 5:379-389.

26. Waaijer ME, Parish WE, Strongitharm BH, Van Heemst D, Slagboom PE, De Craen AJ, Sedivy JM, Westendorp RG, Gunn DA, Maier AB: The number of p16INK4a positive cells in human skin reflects biological age. Aging Cell 2012, 11:722-725.

27. Smogorzewska A, De sLange T: Different telomere damage signaling pathways in human and mouse cells. EMBO J 2002, 21:4338-4348.

28. Minty F, Thurlow JK, Harrison PR, Parkinson EK: Telomere dysfunction in human keratinocytes elicits senescence and a novel transcription profile. Exp Cell Res 2008, 314:2434-2447.

29. Zhang H, Zhao Q, Chen Y, Wang Y, Gao S, Mao Y, Li M, Peng A, He D, Xiao $X$ : Selective expression of S100A7 in lung squamous cell carcinomas and large cell carcinomas but not in adenocarcinomas and small cell carcinomas. Thorax 2008, 63:352-359.

30. Wang J, Sun Q, Morita Y, Jiang H, Gross A, Lechel A, Hildner K, Guachalla LM, Gompf A, Hartmann D, Schambach A, Wuestefeld T, Dauch D, Schrezenmeier H, Hofmann WK, Nakauchi H, Ju Z, Kestler HA, Zender L, Rudolph KL: A differentiation checkpoint limits hematopoietic stem cell self-renewal in response to DNA damage. Cell 2012, 148:1001-1014.

31. Rodier F, Coppe JP, Patil CK, Hoeijmakers WA, Munoz DP, Raza SR, Freund A, Campeau E, Davalos AR, Campisi J: Persistent DNA damage signalling triggers senescence-associated inflammatory cytokine secretion. Nat Cell Biol 2009, 11:973-979.

32. Dulic V, Drullinger LF, Lees $\mathrm{E}$, Reed SI, Stein GH: Altered regulation of G1 cyclins in senescent human diploid fibroblasts: accumulation of inactive cyclin E-Cdk2 and cyclin D1-Cdk2 complexes. Proc Natl Acad Sci U S A 1993, 90:11034-11038.

33. Topley Gl, Okuyama R, Gonzales JG, Conti C, Dotto GP: p21(WAF1/Cip1) functions as a suppressor of malignant skin tumor formation and a determinant of keratinocyte stem-cell potential. Proc Natl Acad Sci U S A 1999, 96:9089-9094.

34. Missero C, Di Cunto F, Kiyokawa H, Koff A, Dotto GP: The absence of p21Cip1/WAF1 alters keratinocyte growth and differentiation and promotes ras-tumor progression. Genes Dev 1996, 10:3065-3075.

35. Wolf R, Mirmohammadsadegh A, Walz M, Lysa B, Tartler U, Remus R, Hengge $U$, Michel G, Ruzicka T: Molecular cloning and characterization of alternatively spliced mRNA isoforms from psoriatic skin encoding a novel member of the S100 family. FASEB J 2003, 17:1969-1971.

36. Wolf R, Ruzicka T, Yuspa SH: Novel S100A7 (psoriasin)/S100A15 (koebnerisin) subfamily: highly homologous but distinct in regulation and function. Amino Acids 2011, 41:789-796

37. Panier S, Ichijima Y, Fradet-Turcotte A, Leung CC, Kaustov L, Arrowsmith CH, Durocher D: Tandem protein interaction modules organize the ubiquitindependent response to DNA double-strand breaks. Mol Cell 2012, 47:383-395.

38. Shiloh Y, Shema E, Moyal L, Oren M: RNF20-RNF40: a ubiquitin-driven link between gene expression and the DNA damage response. FEBS Lett 2011, 585:2795-2802.

39. Muntoni A, Fleming J, Gordon KE, Hunter K, McGregor F, Parkinson EK, Harrison PR: Senescing oral dysplasias are not immortalized by ectopic expression of hTERT alone without other molecular changes, such as loss of INK4A and/or retinoic acid receptor-beta: but p53 mutations are not necessarily required. Oncogene 2003, 22:7804-7808.

40. Coppe JP, Rodier F, Patil CK, Freund A, Desprez PY, Campisi J: Tumor suppressor and aging biomarker p16(INK4a) induces cellular senescence without the associated inflammatory secretory phenotype. J Biol Chem 2011, 286:36396-36403.

41. Blanco R, Munoz P, Flores JM, Klatt P, Blasco MA: Telomerase abrogation dramatically accelerates TRF2-induced epithelial carcinogenesis. Genes Dev 2007, 21:206-220.
42. Biroccio A, Cherfils-Vicini J, Augereau A, Pinte S, Bauwens S, Ye J, Simonet T, Horard B, Jamet K, Cervera L, Mendez-Bermudez A, Poncet D, Grataroli R, De Rodenbeeke CT, Salvati E, Rizzo A, Zizza P, Ricoul M, Cognet C, Kuilman T, Duret H, Lepinasse F, Marvel J, Verhoeyen E, Cosset FL, Peeper D, Smyth MJ, LondonoVallejo A, Sabatier L, Picco V, Pages G, Scoazec JY, Stoppacciaro A, Leonetti C, Vivier E, Gilson E: TRF2 inhibits a cell-extrinsic pathway through which natural killer cells eliminate cancer cells. Nat Cell Biol 2013, 15:818-828.

43. Loughran O, Malliri A, Owens D, Gallimore PH, Stanley MA, Ozanne B, Frame MC, Parkinson EK: Association of CDKN2A/p16INK4A with human head and neck keratinocyte replicative senescence: relationship of dysfunction to immortality and neoplasia. Oncogene 1996, 13:561-568.

44. Hattinger E, Zwicker S, Ruzicka T, Yuspa SH, Wolf R: Opposing functions of psoriasin (S100A7) and koebnerisin (S100A15) in epithelial carcinogenesis. Curr Opin Pharmacol 2013, 13:588-594

45. Deol YS, Nasser MW, Yu L, Zou X, Ganju RK: Tumor-suppressive effects of psoriasin (S100A7) are mediated through the beta-catenin/T cell factor 4 protein pathway in estrogen receptor-positive breast cancer cells. J Biol Chem 2011, 286:44845-44854.

46. Hattori F, Kiatsurayanon C, Okumura K, Ogawa H, Ikeda S, Okamoto K, Niyonsaba F: The antimicrobial protein S100A7/psoriasin enhances expression of keratinocyte differentiation markers and strengthens the skin tight junction barrier. Br J Dermatol 2014, doi:10.1111/bjd.13125. [Epub ahead of print]

47. Gebhardt C, Riehl A, Durchdewald M, Nemeth J, Furstenberger G, Muller-Decker K, Enk A, Arnold B, Bierhaus A, Nawroth PP, Hess J, Angel P: RAGE signaling sustains inflammation and promotes tumor development. J Exp Med 2008, 205:275-285.

48. Freund A, Patil CK, Campisi J: p38MAPK is a novel DNA damage responseindependent regulator of the senescence-associated secretory phenotype. EMBO J 2011, 30:1536-1548.

49. Pitiyage GN, Slijepcevic P, Gabrani A, Chianea YG, Lim KP, Prime SS, Tilakaratne WM, Fortune F, Parkinson EK: Senescent mesenchymal cells accumulate in human fibrosis by a telomere-independent mechanism and ameliorate fibrosis through matrix metalloproteinases. J Pathol 2011, 223:604-617.

50. Gordon KE, Ireland H, Roberts M, Steeghs K, McCaul JA, MacDonald DG, Parkinson EK: High levels of telomere dysfunction bestow a selective disadvantage during the progression of human oral squamous cell carcinoma. Cancer Res 2003, 63:458-467.

51. Parris CN, Jezzard S, Silver A, MacKie R, McGregor JM, Newbold RF: Telomerase activity in melanoma and non-melanoma skin cancer. Br J Cancer 1999, 79:47-53.

52. Gschwandtner M, Zhong S, Tschachler A, Mlitz V, Karner S, Elbe-Burger A, Mildner M: Fetal human keratinocytes produce large amounts of antimicrobial peptides: involvement of histone-methylation processes. J Invest Dermatol 2014, 134:2192-2201.

53. Yu SE, Jang YK: The histone demethylase LSD1 is required for estrogendependent S100A7 gene expression in human breast cancer cells. Biochem Biophys Res Commun 2012, 427:336-342.

54. Schoeftner S, Blanco R, Lopez De Silanes I, Munoz P, Gomez-Lopez G, Flores $J M$, Blasco MA: Telomere shortening relaxes $X$ chromosome inactivation and forces global transcriptome alterations. Proc Natl Acad Sci U S A 2009, 106:19393-19398.

55. Tomas-Loba A, Flores I, Fernandez-Marcos PJ, Cayuela ML, Maraver A, Tejera A, Borras C, Matheu A, Klatt P, Flores JM, Vina J, Serrano M, Blasco $M A$ : Telomerase reverse transcriptase delays aging in cancer-resistant mice. Cell 2008, 135:609-622.

56. Gemenetzidis E, Bose A, Riaz AM, Chaplin T, Young BD, Ali M, Sugden D, Thurlow JK, Cheong SC, Teo SH, Wan H, Waseem A, Parkinson EK, Fortune F, Teh MT: FOXM1 upregulation is an early event in human squamous cell carcinoma and it is enhanced by nicotine during malignant transformation. PLoS One 2009, 4:e4849.

57. Wolf R, Howard OM, Dong HF, Voscopoulos C, Boeshans K, Winston J, Divi R, Gunsior M, Goldsmith P, Ahvazi B, Chavakis T, Oppenheim JJ, Yuspa SH: Chemotactic activity of S100A7 (psoriasin) is mediated by the receptor for advanced glycation end products and potentiates inflammation with highly homologous but functionally distinct S100A15. J Immunol 2008, 181:1499-1506.

doi:10.1186/2046-2395-3-8

Cite this article as: de Castro et al:: The secreted protein S100A7 (psoriasin) is induced by telomere dysfunction in human keratinocytes independently of a DNA damage response and cell cycle regulators. Longevity \& Healthspan 2014 3:8. 